\title{
The Effect and Safety of 5-HT 1 Receptor Agonist Lasmiditan on Migraine: A Systematic Review and Meta-Analysis
}

\author{
Ping Gu, ${ }^{1}$ Cheng Chen $\mathbb{D}^{1,2}$ Qian Wu, ${ }^{1}$ Changhong Dong, ${ }^{3}$ Teng Wang, ${ }^{1}$ Qi Wan $\mathbb{D}^{1}$, \\ and Xin Dong $\mathbb{1}^{1}$ \\ ${ }^{1}$ Department of Neurology, The First Affiliated Hospital of Nanjing Medical University, 300 Guangzhou Road, Nanjing, \\ Jiangsu Province, China \\ ${ }^{2}$ Department of Neurology, The Second Affiliated Hospital of Wannan Medical College, 10 Kangfu Road, Wuhu, \\ Anhui Province, China \\ ${ }^{3}$ Department of Clinical Medicine, Xuzhou Medical University, 209 Tongshan Road, Xuzhou, Jiangsu Province, China
}

Correspondence should be addressed to Qi Wan; chinaqiwan@126.com and Xin Dong; dong_xin123@126.com

Received 22 December 2020; Revised 4 August 2021; Accepted 30 August 2021; Published 7 October 2021

Academic Editor: Fabio Iannotti

Copyright ( 2021 Ping Gu et al. This is an open access article distributed under the Creative Commons Attribution License, which permits unrestricted use, distribution, and reproduction in any medium, provided the original work is properly cited.

\begin{abstract}
Background. Migraine has a great impact on public health. Current acute therapies do not satisfy all migraineurs. The novel serotonin $5-\mathrm{HT}_{1 \mathrm{~F}}$ receptor agonist appears more promising for aborting migraine attacks. Objective. To evaluate the clinical efficacy and safety of lasmiditan in treating acute migraine attacks. Methods. The literature search was performed in PubMed, Embase, and the Cochrane Central Register of Controlled Trials for randomized controlled trials (RCTs) which assessed the effect and safety of lasmiditan on migraine. The risk of bias was assessed using the Cochrane Collaboration's risk of bias tool. Results were extracted and pooled as risk ratios (RRs) with a fixed or random-effects model. Results. Based on the four included RCTs, pooled estimates showed that lasmiditan with the $50 \mathrm{mg}, 100 \mathrm{mg}$, and $200 \mathrm{mg}$ doses was superior to placebo at $2 \mathrm{~h}$ after the first dose in terms of pain freedom, absence of migraine-associated symptoms, headache relief, no/mild disability, and global impression of change (very much/much better) (RRs ranged from 1.13 to 1.96), except for nausea-free and vomiting-free. Both lasmiditan $100 \mathrm{mg}$ and $200 \mathrm{mg}$ resulted in significantly fewer patients using rescue medication $(100 \mathrm{mg}: \mathrm{RR}=0.75,95 \% \mathrm{CI}(0.61,0.92), P=0.007 ; 200 \mathrm{mg}: \mathrm{RR}=0.81,95 \% \mathrm{CI}(0.66,0.99), P=0.04)$ at $2-24 \mathrm{~h}$ postdose, compared with placebo. Safety data showed that the proportion of patients reporting at least one treatment-emergent adverse event (TEAE) and the incidence of most common TEAEs such as dizziness, paresthesia, fatigue, somnolence, and nausea was higher in the lasmiditan groups (50 mg, $100 \mathrm{mg}$, and $200 \mathrm{mg}$ ), compared with placebo. There was no significant difference between lasmiditan and placebo in terms of cardiovascular-related TEAEs ( $R R=2.75,95 \%$ CI $(0.81,9.37), P=0.11)$. Compared with lasmiditan $100 \mathrm{mg}$, lasmiditan $200 \mathrm{mg}$ was more effective in pain freedom at $2 \mathrm{~h}$ after the first dose ( $\mathrm{RR}=0.83,95 \% \mathrm{CI}(0.74,0.94), P=0.004)$ but associated with a higher risk of reporting at least one TEAE $(\mathrm{RR}=0.88,95 \% \mathrm{CI}(0.81,0.96), P=0.006)$. Conclusions. Lasmiditan with the $50 \mathrm{mg}, 100 \mathrm{mg}$, and $200 \mathrm{mg}$ doses are effective and safe in acute migraine treatment. Lasmiditan $200 \mathrm{mg}$ is more effective than lasmiditan $100 \mathrm{mg}$ in pain freedom, while lasmiditan $100 \mathrm{mg}$ is better tolerated in the short-term follow-up. Further larger sample-size RCTs are required to verify the applicability and tolerability in the long term.
\end{abstract}

\section{Introduction}

Migraine is a common chronic disabling neurological disorder, characterized by unilateral moderate to severe headache attacks and accompanied by nausea, vomiting, photophobia, and phonophobia [1]. In the Global Burden of Disease Study 2016, migraine is reported as the second most disabling dis- order, which reduced quality of life and increased the use of health resources $[2,3]$. Acute migraine treatment is aimed at relieving pain and abort headache attack [4]. The present acute migraine therapy contains specific (ergots, triptans) and nonspecific drugs (nonsteroidal anti-inflammatory drugs) [5]. However, it should be noted that $40 \%$ of episodic migraineurs are not satisfied with the effects of acute 
treatments, which might lead to a high risk of medication overuse headache and exacerbations of headache [6].

Triptans acting on the $5-\mathrm{HT}_{1 \mathrm{~B} / 1 \mathrm{D}}$ receptors are the firstline choice in the acute treatment for migraine attack currently, which were introduced into the clinical application in the early 1990s and represented a milestone in acute antimigraine therapy [7]. All oral triptans at marketed doses were effective by constricting extracerebral and intracranial vessels, inhibiting trigeminal neurons, and blocking plasma protein extravasation [8]. However, up to $35 \%$ of patients with episodic migraine do not benefit from triptans. Also, triptans are contraindicated in migraineurs with myocardial infarction, coronary artery disease, stroke, uncontrolled hypertension, and vasculitis because of their potential for vasoconstriction [9].

Although the pathophysiology of migraine has not been fully understood, trigeminal pathways have been proposed to be involved in the pathogenesis of migraine for decades [10]. Neural inhibition of the $5-\mathrm{HT}_{1 \mathrm{~F}}$ receptor expressed in the trigeminal ganglia would provide a potential alternative to treat acute migraine with nonvascular mechanism [11]. Lasmiditan (COL-144, LY573144), a novel highly selective $5-\mathrm{HT}_{1 \mathrm{~F}}$ receptor agonist, is currently in phase III trials for acute migraine therapy. It has a much higher affinity ( $>470$-fold) for the $5-\mathrm{HT}_{1 \mathrm{~F}}$ than $5-\mathrm{HT}_{1 \mathrm{~B} / \mathrm{D}}$ receptors in vivo binding studies [12]. Phase II and phase III clinical trials of lasmiditan showed a significantly better treatment response and a higher incidence of the central nervous system- (CNS-) related adverse events than the placebo, especially in high-dose groups [13]. The US Food and Drug Administration has approved the use of $100 \mathrm{mg}$ and $200 \mathrm{mg}$ doses of lasmiditan for acute treatment of migraine attacks with or without aura [14]. However, there is no systematic evaluation of the clinical efficacy and safety of different dosages of lasmiditan quantificationally. Thus, we performed a systematic review and meta-analysis of randomized controlled trials (RCTs) on the efficacy and safety of different doses of lasmiditan for acute migraine treatment.

\section{Methods}

2.1. Study Design and Registration. The meta-analysis adhered to the requirements of the Preferred Reporting Items for Systematic Reviews and Meta-analysis (PRISMA) statement (S1 File). This review protocol was registered in the International Prospective System Reviews (No. CRD42020188661).

2.2. Search Strategy and Inclusion Criteria. Two reviewers (Dong and Chen) independently searched PubMed, Embase, and the Cochrane Central Register of Controlled Trials to identify the studies published up to May 2020. The complete search strategy was presented in S2 File. We further tracked the reference lists of retrieved articles and identified relevant grey literature and conference abstracts. We screened all trials satisfying the following inclusion criteria: treatment of migraine attacks in adult migraineurs with or without aura defined according to the International Classification of Headache Disorders, third edition or second edition; treatment with an oral or intravenous lasmiditan; random- ized, double-blinded, controlled (placebo) clinical trials; aimed to evaluate the efficacy and safety of lasmiditan for acute treatment of migraine. The disagreement between the two reviewers would be resolved by consultation with a third author $(\mathrm{Gu})$.

2.3. Quality Assessment. Two investigators assessed the methodological quality of included studies, respectively, by using the Cochrane Collaboration's risk of bias tool for systematic reviews $[15,16]$. The domains in the Cochrane Collaboration's tool for assessing the risk of bias included random sequence generation, allocation concealment, blinding of participants and personnel, blinding of outcome assessment, incomplete outcome data, selective reporting, and other biases. The bias of each item was judged as a low risk of bias, a high risk of bias, or an unclear risk of bias. Disagreements were resolved by discussing with the corresponding author (Wan).

2.4. Data Extractions. Efficacy data and adverse events for lasmiditan and placebo were extracted independently by two reviewers (Dong and Chen) using the predefined data extraction form. Only data above the dose ( $\geq 20 \mathrm{mg}$ intravenous or $50 \mathrm{mg}$ oral) in the experimental group was included in this meta-analysis. Two different delivery routes, including oral and intravenous, were adopted in our included trials. Conversion of intravenous doses into oral doses was achieved according to bioavailability, reported as approximately $40 \%$ [17]. Any discrepancies among the two reviewers were resolved through discussion or consensus with a third reviewer $(\mathrm{Gu})$. We extracted the characteristics of each RCT recorded as follows: first author, publication year, diagnostic criteria, study population characteristics (age, sex, and ethnicity), intervention (placebo or lasmiditan with different doses), and baseline headache characteristics of migraineurs (migraine attacks per month). The primary outcome included pain freedom and absence of migraineassociated symptoms at $2 \mathrm{~h}$ after the first dose. The secondary outcomes included headache relief, no/mild disability, the global impression of change (very much/much better) at $2 \mathrm{~h}$ after the first dose, and rescue medication from 2 to $24 \mathrm{~h}$ postdose. Treatment-emergent adverse events (TEAEs) after the first dose were recorded to assess the safety of lasmiditan, including the proportion of patients with TEAEs (at least one), the incidence of the most common TEAEs (dizziness, paresthesia, fatigue, lethargy, and nausea), and cardiovascular-related TEAEs. The related data reported incompletely in the articles was extracted from the Clinical trials.gov.

2.5. Statistical Analysis. The data about the responder rate in efficacy and adverse events were dichotomous. The relative risk (RR) with 95\% confidence intervals (CIs) was used to estimate the efficacy and safety using the Mantel-Haenszel (M-H) method. The statistical heterogeneity was assessed by the chi-squared test, and its extent was measured by the $I^{2}$ statistic. For the chi-squared test, a significance level was set at $P<0.10$. If the $I^{2}$ value was greater than $50 \%$, we believed that there might be a significant heterogeneity, 
and $I^{2}$ less than $50 \%$ indicated no significant heterogeneity [18]. When there was no significant heterogeneity, we used a fixed-effects model for pooling the data; otherwise, a random-effects model was used. Sensitivity analysis attempted to identify the source of heterogeneity by excluding any single hazard ratio from the analysis data subsequently. According to the frequently investigated doses of lasmiditan (50 mg, $100 \mathrm{mg}$, and $200 \mathrm{mg}$ ), we performed a pooled analysis to assess the effects of lasmiditan against placebo and between different dosages of lasmiditan. Metaregression would not be considered in this meta-analysis because of fewer included studies (less than 10). We did not access publication bias by a visual assessment of a funnel plot, Egger, or Begg test attributing to fewer included trials (less than 10) $[19,20]$. All meta-analyses were performed using the software RevMan 5.3 (Cochrane Collaboration, Oxford, England). $P<0.05$ was considered statistically significant.

\section{Results}

3.1. Study Selection and Inclusion. The trial selection process was presented in the PRISMA flow chart (Figure 1). We identified 200 articles in the database searches according to the search strategy. 108 articles remained after removing the duplicated publication, and only 38 articles remained after title and abstract screening. 34 articles were excluded because of their nature as review, letter, or postanalysis of clinical trials. Ultimately, four RCTs involving 4920 participants were included in this meta-analysis [21-24].

3.2. Study Characteristics. All four trials were multicenter, 1double-blind RCTs, published between 2010 and 2019 [21-24]. Participants were diagnosed with migraine based on the IHS criteria. All eligible patients were adults $(\geq 18$ years), with a mean age of 42.17 years, and $84.29 \%$ were female. The mean migraine attacks per month reported at baseline was 5.06. Lasmiditan was used to treat a single acute migraine attack in all trials. A total of 764 patients were randomized to lasmiditan $50 \mathrm{mg}$ (oral and intravenous administration), 1347 to lasmiditan $100 \mathrm{mg}, 1329$ to lasmiditan $200 \mathrm{mg}$, and 1390 to placebo. Three studies adopted oral delivery routes, and only one trial evaluated the efficacy of intravenous lasmiditan. The characteristics of the four included studies are summarized in Table 1.

3.3. Quality of the Included Studies. The quality assessments of the included four RCTs are summarized in Figure 2, according to the Cochrane Collaboration's tool for assessing the risk of bias. As shown in Figure 2, all subjects were randomized to receive lasmiditan and placebo according to the randomized sequence generated by central randomization or computer randomization system. All studies reported allocation concealment. Therefore, we judged these studies as having a low risk of selection bias. Each subcenter investigator and patient were masked from treatment selection during the study. Only one study by Ferrari et al. [21] reported that the pharmacist was aware of the drug dilution, but the pharmacist was independent of the investigator. Thus, the risk of performance bias was judged as low. We rated all studies at low risk of detection bias since all studies used the headache diary to record responses before and after the study drug intake. The loss rate was balanced among groups and did not exceed $10 \%$. The intention-to-treat analyses were utilized in all studies. Therefore, the risk of attrition bias and reporting bias were judged as low in all included studies. Due to the dose-adaptation design in the study by Ferrari et al. [21] and many patients with vascular risks in the studies by Kuca et al. [23] and Goadsby et al. [24], other biases in these included studies were considered to be at unclear risk. Overall, the included studies were suitable for the metaanalysis of the effect and safety of lasmiditan for migraine.

\subsection{Primary Outcomes}

3.4.1. Pain Freedom at $2 \mathrm{~h}$. Pain freedom at $2 \mathrm{~h}$ was reported in all included trials. Pain freedom in migraineurs at $2 \mathrm{~h}$ referred to headache pain-free at $2 \mathrm{~h}$ after the first dose and before any rescue medication [25]. The pooled data analyzed with a fixed-effects model demonstrated that the percentage of patients achieving pain-free was higher in the $50 \mathrm{mg}, 100 \mathrm{mg}$, and $200 \mathrm{mg}$ lasmiditan dose groups than in the placebo group (50 mg: $\mathrm{RR}=1.38,95 \%$ CI $(1.13,1.68), P=0.002 ; 100 \mathrm{mg}$ : $\mathrm{RR}=1.63,95 \%$ CI $(1.40,1.91), P<0.00001 ; 200 \mathrm{mg}: \mathrm{RR}=$ 1.96, 95\% CI $(1.69,2.27), P<0.00001)$ (Figure 3$)$. Both the $50 \mathrm{mg} \quad(\mathrm{RR}=0.74,95 \% \mathrm{CI}(0.62,0.87), P=0.0003)$ and $100 \mathrm{mg}(\mathrm{RR}=0.83,95 \% \mathrm{CI}(0.74,0.94), P=0.004)$ doses of lasmiditan were inferior to $200 \mathrm{mg}$ dose of lasmiditan in terms of pain freedom at $2 \mathrm{~h}$ after the first dose (Figure 4 ). No significant difference was detected between the $50 \mathrm{mg}$ and $100 \mathrm{mg}$ lasmiditan dose group, based on two RCTs. There was no heterogeneity between studies $\left(I^{2}=0 \%\right)$.

3.4.2. Absence of Migraine-Associated Symptoms at $2 \mathrm{~h}$. Migraine-associated symptoms included nausea, vomiting, photophobia, and photophobia were reported in four included RCTs. Compared with placebo, migraineurs treated with lasmiditan reported a higher response rate of phonophobia-free (50 mg: $\mathrm{RR}=1.13,95 \%$ CI $(1.05,1.22), P=0.002 ; 100 \mathrm{mg}: R$ $R=1.16$, 95\% CI $(1.10,1.22), P<0.00001 ; 200 \mathrm{mg}: \mathrm{RR}=$ $1.16,95 \%$ CI $(1.10,1.22), P<0.00001)$ and photophobiafree $(50 \mathrm{mg}: \mathrm{RR}=1.19$, 95\% CI $(1.04,1.37), \quad P=0.01$; $100 \mathrm{mg}: \quad \mathrm{RR}=1.35, \quad 95 \% \quad \mathrm{CI} \quad(1.17, \quad 1.57), \quad P<0.0001$; $200 \mathrm{mg}: \mathrm{RR}=1.30,95 \% \mathrm{CI}(1.04,1.40), P<0.00001)$ at 2 hours after dosing (Table 2). However, the RRs for nauseafree and vomiting-free did not favor lasmiditan over placebo. Both lasmiditan $100 \mathrm{mg}(\mathrm{RR}=0.91,95 \%$ CI $(0.84,0.98)$, $P=0.02)$ and $200 \mathrm{mg}(\mathrm{RR}=1.12,95 \% \mathrm{CI}(1.04,1.22)$, $P=0.005)$ resulted in a significantly higher rate of photophobia-free at $2 \mathrm{~h}$ after the first dose, as compared with lasmiditan $50 \mathrm{mg}$. There was significant heterogeneity in the estimates of $100 \mathrm{mg}$ lasmiditan for photophobia-free $\left(I^{2}=72 \%\right)$. Sensitivity analysis showed that the heterogeneity could be resolved by excluding the study by Färkkilä et al. [22] from the pooled data with little change of the overall effect. The heterogeneity might be caused by the characteristics of participants, relatively small sample size, and the discrepancy in the evaluation criteria in the trial by Färkkilä et al. [22]. 


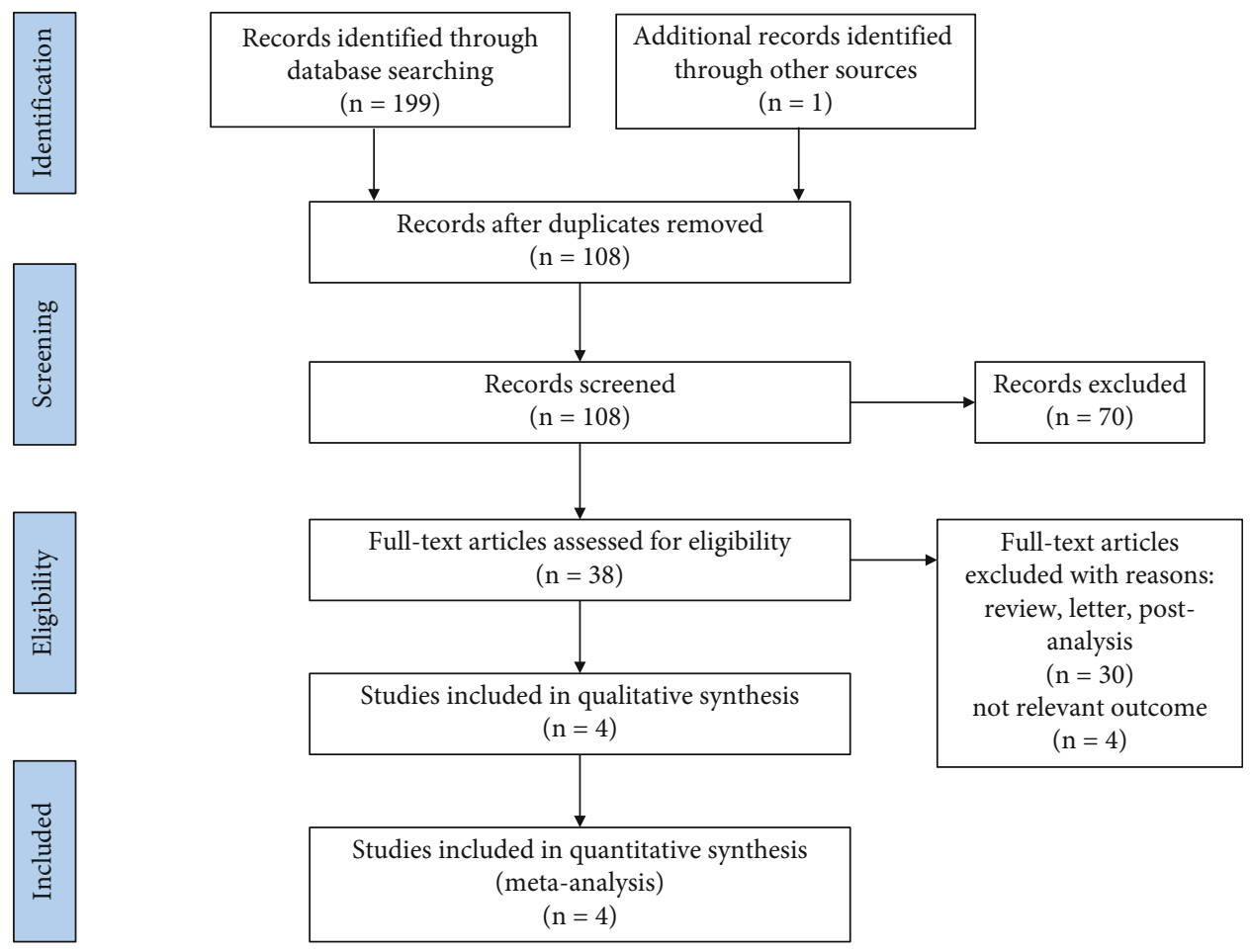

FIGURE 1: Process of identifying eligible studies for the meta-analysis.

The headache severity and the proportion of migraine without aura were higher than in the other included trials.

\subsection{Secondary Outcomes}

3.5.1. Headache Relief at $2 \mathrm{~h}$. The RRs of headache relief at $2 \mathrm{~h}$ after treatment favored lasmiditan over placebo (50 mg: $\mathrm{RR}=1.27,95 \%$ CI $(1.15,1.41), P<0.00001 ; 100 \mathrm{mg}: \mathrm{RR}=$ $1.51,95 \%$ CI $(1.25,1.82), P<0.0001 ; 200 \mathrm{mg}: \mathrm{RR}=1.41$, $95 \%$ CI $(1.28,1.54), P<0.00001)$ (Table 3$)$. There was statistically significant heterogeneity in headache relief among trials when compared lasmiditan $100 \mathrm{mg}$ with placebo $\left(I^{2}=75 \%\right)$. Sensitivity analysis showed that heterogeneity could be resolved by removing the study by Färkkilä et al. [22] from the pooled data, with no significant effect on the pooled estimate. No significant difference was detected among any dose comparisons in headache relief at $2 \mathrm{~h}$ (Table 3).

3.5.2. No/Mild Disability at $2 \mathrm{~h}$. As shown in Table 3, all three doses of lasmiditan (50 mg, $100 \mathrm{mg}$, and $200 \mathrm{mg}$ ) resulted in significantly more patients achieving no/mild disability at $2 \mathrm{~h}$ after the first dose $(50 \mathrm{mg}: \mathrm{RR}=1.13,95 \% \mathrm{CI}$ (1.03, 1.25), $P=0.01 ; 100 \mathrm{mg}: \mathrm{RR}=1.23$, 95\% CI (1.08, $1.40), P=0.001 ; 200 \mathrm{mg}: \mathrm{RR}=1.16,95 \%$ CI $(1.03,1.30)$, $P=0.01)$, compared to the placebo group. Compared with the $50 \mathrm{mg}$ lasmiditan group, the proportion of patients who achieved no/mild disability at $2 \mathrm{~h} \quad(\mathrm{RR}=0.90,95 \%$ CI $(0.82,0.98), P=0.01)$ was significantly higher in the $100 \mathrm{mg}$ lasmiditan group. No significant differences were detected among other dose comparisons. We found significant heterogeneity among the studies for comparing las- miditan $100 \mathrm{mg}$ with placebo. Sensitivity analysis showed that the heterogeneity could be reduced by excluding the study by Färkkilä et al. [22] from the pooled data with little change of the overall outcome.

3.5.3. Global Impression of Change (Very Much/Much Better) at 2 h. Lasmiditan $50 \mathrm{mg}(\mathrm{RR}=1.33$, 95\% CI $(1.13,1.55), P=$ $0.0004), 100 \mathrm{mg}(\mathrm{RR}=1.60,95 \% \mathrm{CI}(1.42,1.81), P<0.00001)$, and $200 \mathrm{mg}(\mathrm{RR}=1.62,95 \% \mathrm{CI}(1.43,1.82), P<0.00001)$ were associated with more patients achieving global impression of change (very much/much better), compared with placebo at $2 \mathrm{~h}$ after the first dose (Table 3 ). There was no significant heterogeneity between studies. Lasmiditan $100 \mathrm{mg}(\mathrm{RR}=0.86$, 95\% CI $(0.75,0.99), P=0.04)$ and $200 \mathrm{mg}(\mathrm{RR}=1.16,95 \%$ CI $(1.01,1.34), P=0.03)$ resulted in more patients achieving global impression of change (very much/much better) at $2 \mathrm{~h}$ after the first dose when compared with lasmiditan $50 \mathrm{mg}$. No significant difference was detected when comparing lasmiditan $100 \mathrm{mg}$ with $200 \mathrm{mg}$, based on three RCTs (Table 3).

3.5.4. Use of Rescue Medication (2-24h). Compared with placebo, lasmiditan $100 \mathrm{mg}(\mathrm{RR}=0.75,95 \% \mathrm{CI}(0.61,0.92)$, $P=0.007)$ and $200 \mathrm{mg}(\mathrm{RR}=0.81,95 \% \mathrm{CI}(0.66,0.99)$, $P=0.04)$ resulted in significantly fewer patients using rescue medication at 2-24h. There was no heterogeneity between studies $\left(I^{2}=0 \%\right)$. No significant difference was detected between lasmiditan $50 \mathrm{mg}$ and placebo, or among other dose comparisons in the proportion of patients using rescue medication (Table 3).

3.6. Adverse Events. No deaths were reported in the four trials. All the included RCTs reported the incidence rates 
TABLE 1: Characteristics of the included studies.

\begin{tabular}{|c|c|c|c|c|c|c|c|c|}
\hline $\begin{array}{l}\text { Included } \\
\text { trials }\end{array}$ & $\begin{array}{l}\text { Eligibility } \\
\text { criteria }\end{array}$ & $\begin{array}{l}\text { Intervention } \\
\text { groups }\end{array}$ & $\begin{array}{c}\text { Gender } \\
\text { Female/male } \\
(n)\end{array}$ & $\begin{array}{l}\text { Mean } \\
\text { age } \\
\text { (years) }\end{array}$ & $\begin{array}{l}\text { White } \\
\text { ethnic } \\
n(\%)\end{array}$ & $\begin{array}{l}\text { Migraines per month } \\
\text { Mean (SD) }\end{array}$ & Efficacy outcome & $\begin{array}{l}\text { Adverse } \\
\text { events }\end{array}$ \\
\hline \multirow{3}{*}{$\begin{array}{l}\text { Kuca } \\
\text { et al., } \\
2018[23]\end{array}$} & \multirow{3}{*}{$\begin{array}{c}\text { IHS } 1.1 \\
\text { and } 1.2 .1 \\
\left(3^{\text {rd }} \text { edition }\right)\end{array}$} & Placebo & $525 / 92$ & 42.4 & $479(77.6 \%)$ & $5.1(1.8)$ & $\begin{array}{l}\text { Headache pain-free; } \\
\text { MBS free; }\end{array}$ & $\begin{array}{l}\text { Dizziness; } \\
\text { fatigue }\end{array}$ \\
\hline & & $\begin{array}{l}\text { Lasmiditan } \\
100 \mathrm{mg}\end{array}$ & $512 / 118$ & 42.2 & $471(74.8 \%)$ & $5.1(1.8)$ & $\begin{array}{l}\text { Sustained pain- } \\
\text { freedom } \\
\text { at } 24 \mathrm{~h} / 48 \mathrm{~h} ;\end{array}$ & $\begin{array}{c}\text { Paresthesia; } \\
\text { nausea }\end{array}$ \\
\hline & & $\begin{array}{l}\text { Lasmiditan } \\
200 \mathrm{mg}\end{array}$ & $515 / 94$ & 41.4 & $450(73.9 \%)$ & $5.3(2.3)$ & $\begin{array}{l}\text { Headache relief at } 2 \mathrm{~h} \text {; } \\
\text { nausea/vomiting/ } \\
\text { phonophobia/ } \\
\text { photophobia-free } \\
\text { at } 2 \mathrm{~h}\end{array}$ & $\begin{array}{l}\text { Lethargy; } \\
\text { somnolence }\end{array}$ \\
\hline \multirow{5}{*}{$\begin{array}{l}\text { Färkkilä } \\
\text { et al., } \\
2012 \text { [22] }\end{array}$} & \multirow{5}{*}{$\begin{array}{c}\text { IHS } 1.1 \\
\text { and } 1.2 .1 \\
\left(2^{\text {nd }} \text { edition }\right)\end{array}$} & Placebo & $75 / 11$ & 40.5 & $86(100 \%)$ & $3.1(1.7)$ & $\begin{array}{c}\text { Headache response } \\
\text { at } 2 \mathrm{~h}\end{array}$ & $\begin{array}{l}\text { Dizziness; } \\
\text { fatigue }\end{array}$ \\
\hline & & $\begin{array}{l}\text { Lasmiditan } \\
50 \mathrm{mg}\end{array}$ & $69 / 13$ & 40.4 & $81(99 \%)$ & $3.3(1.6)$ & Pain-free at $2 \mathrm{~h}$ & $\begin{array}{l}\text { Paresthesia; } \\
\text { nausea }\end{array}$ \\
\hline & & $\begin{array}{l}\text { Lasmiditan } \\
100 \mathrm{mg}\end{array}$ & $68 / 14$ & 42.0 & $81(99 \%)$ & $3.3(1.7)$ & $\begin{array}{c}\text { Headache recurrence } \\
\text { within } 24 \mathrm{~h}\end{array}$ & Vertigo \\
\hline & & $\begin{array}{l}\text { Lasmiditan } \\
200 \mathrm{mg}\end{array}$ & $65 / 6$ & 39.5 & $70(99 \%)$ & $3.3(1.9)$ & $\begin{array}{l}\text { Rescue drug 2-24 h; } \\
\text { patient's global }\end{array}$ & $\begin{array}{c}\text { Sensation of } \\
\text { heaviness }\end{array}$ \\
\hline & & $\begin{array}{l}\text { Lasmiditan } \\
\quad 400 \mathrm{mg}\end{array}$ & $65 / 5$ & 38.7 & $69(99 \%)$ & $3.1(1.6)$ & $\begin{array}{l}\text { Impression (much or } \\
\text { very much better) at } 2 \mathrm{~h}\end{array}$ & Somnolence \\
\hline \multirow{4}{*}{$\begin{array}{l}\text { Ferrari } \\
\text { et al., } \\
2010[21]\end{array}$} & \multirow{4}{*}{$\begin{array}{c}\text { IHS } 1.1 \\
\text { and } 1.2 .1 \\
\left(2^{\text {nd }} \text { edition }\right)\end{array}$} & Placebo & $38 / 4$ & 40.3 & $42(100 \%)$ & 3.3 & $\begin{array}{c}\text { Headache response } \\
\text { at } 2 \mathrm{~h}\end{array}$ & $\begin{array}{l}\text { Dizziness; } \\
\text { fatigue }\end{array}$ \\
\hline & & $\begin{array}{l}\text { Lasmiditan } \\
20 \mathrm{mg} \text { (iv) }\end{array}$ & $24 / 4$ & 38.9 & $28(100 \%)$ & 3.3 & Pain-free at $2 \mathrm{~h}$ & Paresthesia \\
\hline & & $\begin{array}{l}\text { Lasmiditan } \\
30 \text { mg (iv) }\end{array}$ & $14 / 2$ & 40.3 & $16(100 \%)$ & 3.5 & $\begin{array}{l}\text { Sustained pain } \\
\text { response }\end{array}$ & $\begin{array}{c}\text { Sensation of } \\
\text { heaviness }\end{array}$ \\
\hline & & $\begin{array}{l}\text { Lasmiditan } \\
45 \mathrm{mg} \text { (iv) }\end{array}$ & $3 / 1$ & 40.8 & $4(100 \%)$ & 2.8 & $\begin{array}{l}\text { Sustained pain free; } \\
\text { nausea/photophobia/ } \\
\text { phonophobia } 2 \mathrm{~h}\end{array}$ & $\begin{array}{l}\text { Feeling of } \\
\text { relaxation }\end{array}$ \\
\hline \multirow{4}{*}{$\begin{array}{l}\text { Goadsby } \\
\text { et al., } \\
2019 \text { [24] }\end{array}$} & \multirow{4}{*}{$\begin{array}{c}\text { IHS } 1.1 \\
\text { and } 1.2 .1 \\
\left(3^{\text {rd }} \text { edition }\right)\end{array}$} & Placebo & $545 / 100$ & 42.6 & $516(80.0 \%)$ & $5.5(2.4)$ & $\begin{array}{l}\text { Headache pain-free } \\
\text { at } 2 \mathrm{~h}\end{array}$ & $\begin{array}{l}\text { Dizziness; } \\
\text { fatigue }\end{array}$ \\
\hline & & $\begin{array}{l}\text { Lasmiditan } \\
\quad 50 \mathrm{mg}\end{array}$ & $554 / 100$ & 42.8 & $524(80.1 \%)$ & $5.2(2.0)$ & MBS-free at $2 \mathrm{~h}$ & $\begin{array}{c}\text { Paresthesia; } \\
\text { nausea }\end{array}$ \\
\hline & & $\begin{array}{l}\text { Lasmiditan } \\
100 \mathrm{mg}\end{array}$ & $539 / 96$ & 43.4 & $509(80.2 \%)$ & $5.3(1.9)$ & $\begin{array}{c}\text { Sustained pain-free } \\
\text { at } 24 \mathrm{~h}\end{array}$ & Somnolence \\
\hline & & $\begin{array}{l}\text { Lasmiditan } \\
200 \mathrm{mg}\end{array}$ & $536 / 113$ & 41.8 & $522(80.4 \%)$ & $5.3(1.9)$ & $\begin{array}{c}\text { Headache pain relief at } \\
2 \mathrm{~h} \text {; nausea/ } \\
\text { phonophobia/ } \\
\text { photophobia/vomiting } \\
\text { free at } 2 \mathrm{~h}\end{array}$ & Lethargy \\
\hline
\end{tabular}

IHS: International Headache Society; MBS: most bothersome symptom; SD: standard deviation; iv: injection of vein.

of the most common TEAEs. In this meta-analysis, three RCTs were evaluated for the proportion of patients who reported at least one TEAE, and two RCTs reported the cardiovascular-related TEAEs. The most common TEAEs in the trials after dosing were CNS-related TEAEs including dizziness, paresthesia, fatigue, somnolence, and nausea.

3.6.1. At Least One TEAE. A higher proportion of patients reported at least one TEAE after the first dose in the $50 \mathrm{mg}$ $(\mathrm{RR}=2.40,95 \%$ CI $(1.83,3.13), \quad P<0.00001), 100 \mathrm{mg}$ $(\mathrm{RR}=2.74,95 \% \mathrm{CI}(2.11,3.55), P<0.00001)$, and $200 \mathrm{mg}$ lasmiditan dose groups $(\mathrm{RR}=3.11,95 \% \mathrm{CI}(2.49,3.89)$,
$P<0.00001$ ), as compared with the placebo group (Figure 5). Compared with lasmiditan $200 \mathrm{mg}$, we found lasmiditan $50 \mathrm{mg}(\mathrm{RR}=0.67,95 \% \mathrm{CI}(0.59,0.77), P<0.00001)$ and $100 \mathrm{mg}(\mathrm{RR}=0.88,95 \% \mathrm{CI}(0.81,0.96), P=0.006)$ resulted in significantly fewer patients reporting at least one TEAE (S3 File). There was significant between-study heterogeneity (100 mg: $I^{2}=63 \%$; $200 \mathrm{mg}: I^{2}=53 \%$ ). Removing the study by Kuca et al. [23] from the pooled data, the heterogeneity could be reduced.

3.6.2. Most Common TEAEs. As summarized in Table 4, patients treated with lasmiditan at each dose reported higher 


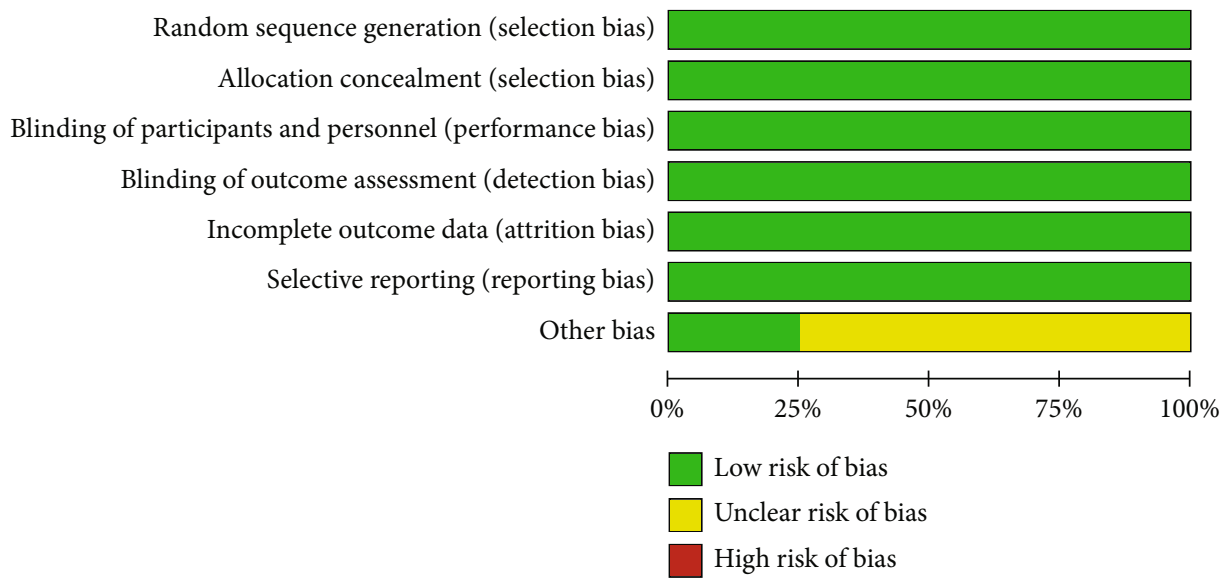

FIGURE 2: Risk of bias for included trials.

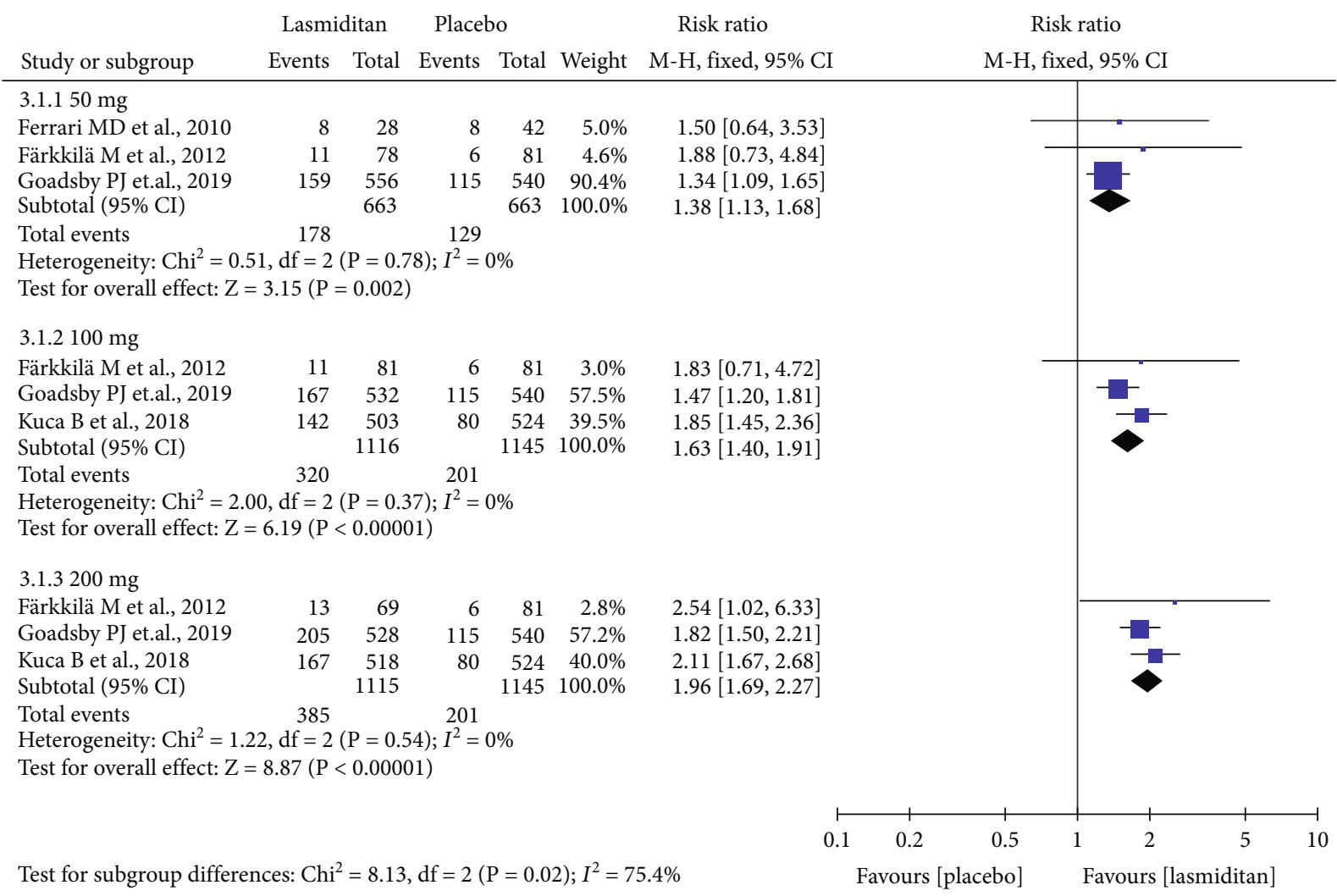

Figure 3: Forest plot: responder rate for pain freedom at $2 \mathrm{~h}$ of lasmiditan versus placebo after the first dose (50 mg, $100 \mathrm{mg}$, and $200 \mathrm{mg}$ ).

incidence rates of the most common TEAEs (dizziness, paresthesia, fatigue, somnolence, and nausea) than with placebo, except for nausea in the lasmiditan $100 \mathrm{mg}$ dose group. A higher proportion of patients reported dizziness, paresthesia, and fatigue after the first dose in the $200 \mathrm{mg}$ lasmiditan dose group compared to the $50 \mathrm{mg}$ lasmiditan dose group. Compared with the lasmiditan $50 \mathrm{mg}$ group, patients in the lasmiditan $100 \mathrm{mg}$ group had a higher incidence rate of paresthesia. We found no significant difference in the incidence rates of the most common TEAEs when comparing lasmidi$\tan 100 \mathrm{mg}$ with $200 \mathrm{mg}$. There was significant heterogeneity between the trials in the estimates of $100 \mathrm{mg}$ lasmiditan for dizziness and nausea after dosing. Removing the study by Kuca et al. [23], the heterogeneity between the studies could be reduced.

3.6.3. Cardiovascular-Related TEAEs. Two RCTs reported the cardiovascular-related TEAEs. The risk of cardiovascularrelated TEAEs was not significantly higher in lasmiditan treatment groups compared with placebo $(\mathrm{RR}=2.75,95 \% \mathrm{CI}$ $(0.81,9.37), P=0.11)$. There was no heterogeneity between studies $\left(I^{2}=0 \%\right)$ (Figure 6$)$. 
(a) $50 \mathrm{mg}$ versus $100 \mathrm{mg}$

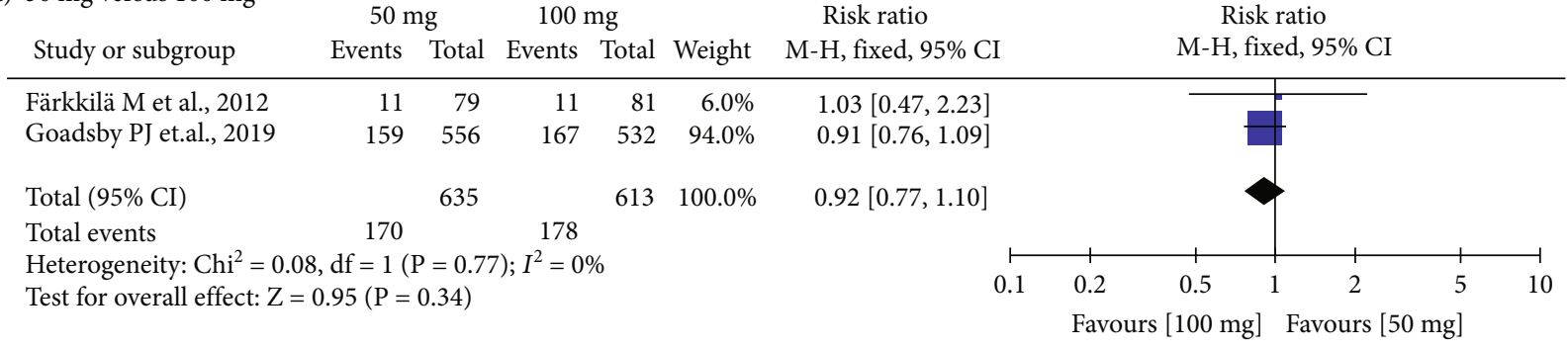

(b) $100 \mathrm{mg}$ versus $200 \mathrm{mg}$

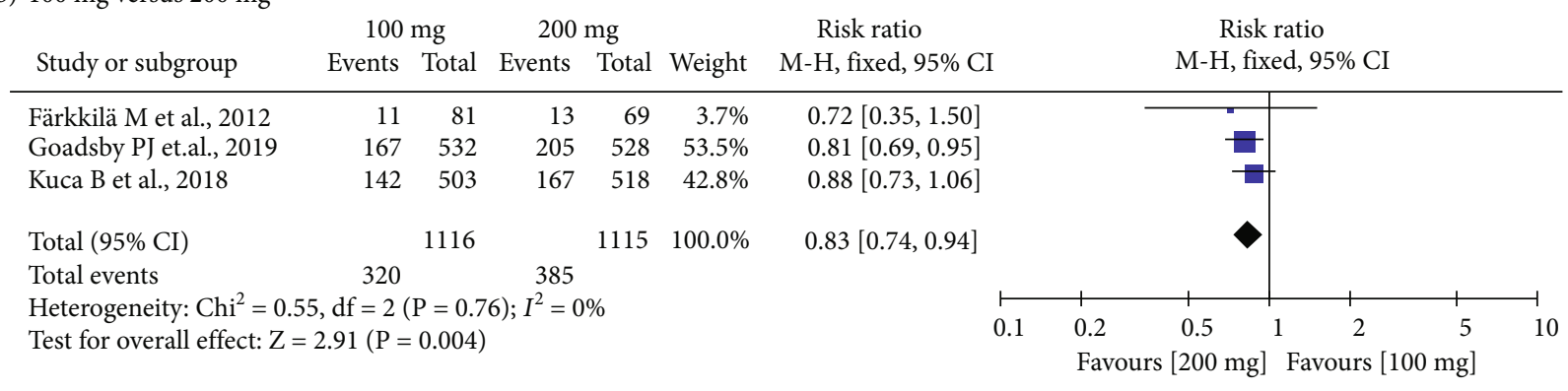

(c) $200 \mathrm{mg}$ versus $50 \mathrm{mg}$

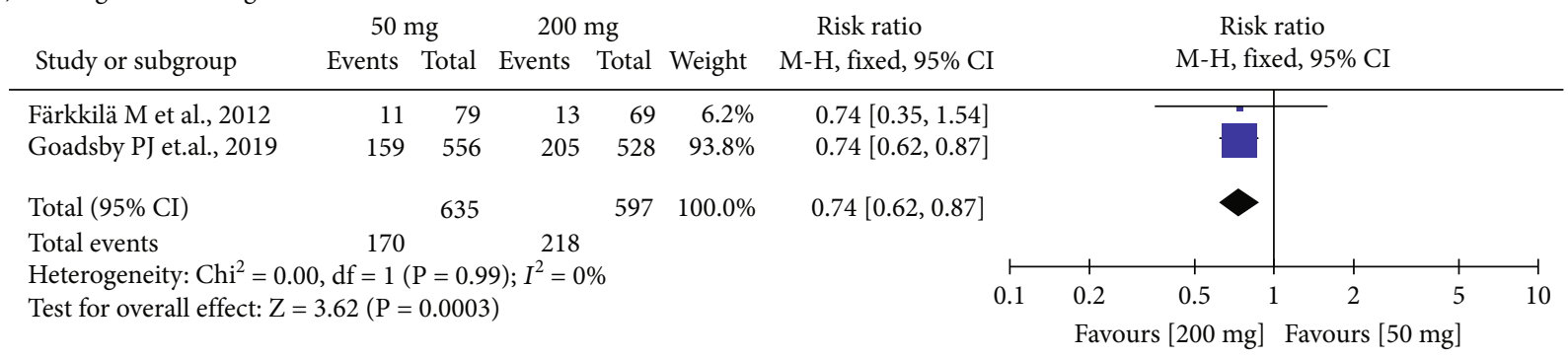

FIGURE 4: Forest plot: responder rate for pain freedom between different dosage comparisons at $2 \mathrm{~h}$ after the first dose.

\section{Discussion}

Our meta-analysis presented that lasmiditan is a promising therapeutic option for aborting migraine attacks by assessing the efficacy and safety of lasmiditan. Lasmiditan, an emerging selective $5-\mathrm{HT}_{1 \mathrm{~F}}$ receptor agonist, could cross the blood-brain barrier (BBB) and inhibit dural plasma protein extravasation by acting on the $5-\mathrm{HT}_{1 \mathrm{~F}}$ receptors expressed in trigeminal neurons, trigeminal ganglion, and trigeminal caudal nucleus, which are not expressed in vascular endothelial cells or smooth muscle cells of the brain [26]. The clinical efficacy of lasmiditan without vasoconstrictive activity implies that vasoconstriction is not essential for antimigraine therapy and strengthens the established neurogenic hypothesis that the trigeminal nerve system may be involved in central neuronal mechanisms of migraine pathophysiology. Considering the structural and pharmacological differences between lasmiditan and triptans [12, 27], lasmiditan is probably more suitable for migraineurs with insufficient response or contraindications for triptan.

In the case of outcomes being reported at multiple time points in some trials, the outcome measures of efficacy at $2 \mathrm{~h}$ after drug intake would be extracted because of the maximum serum concentration following oral administration [17]. Lasmiditan with the $50 \mathrm{mg}, 100 \mathrm{mg}$, and $200 \mathrm{mg}$ was superior to placebo in terms of pain freedom, photophobia-free, phonophobia-free, headache relief, no/mild disability, and global impression of change in acute treatment of migraine at $2 \mathrm{~h}$ postdose except nausea-free and vomitingfree. Lasmiditan $100 \mathrm{mg}$ or $200 \mathrm{mg}$ had superior efficacy as measured by the use of rescue medication. Nausea and/or vomiting symptoms were not only migraine-associated symptoms but also drug-induced adverse effects, such as treatment-emergent nausea or vomiting postdose [25]. The difficulty in identifying whether nausea and/or vomiting resulted from unrelieved migraine-associated symptoms or unavoidable drug-induced adverse effects probably contributed to no advantage of lasmiditan for nausea-free and vomiting-free compared with placebo. Triptans produce a headache response at $2 \mathrm{~h}$ in $60 \%$ of migraine patients, and $30 \%$ of migraineurs are pain freedom at $2 \mathrm{~h}$ [8]. According to the overall pooled data, lasmiditan produces headache relief at $2 \mathrm{~h}$ in $61.05 \%$ of migraineurs, and $30.48 \%$ of migraineurs are pain freedom at $2 \mathrm{~h}$. For lasmiditan, the effect of acute migraine treatment in terms of pain freedom and headache relief may be equivalent to triptans. Future welldesigned studies should be provided for a head-to-head comparison between lasmiditan and triptans. This metaanalysis evaluated the short-term outcomes for a single attack of migraine with lasmiditan. Studies with continued 


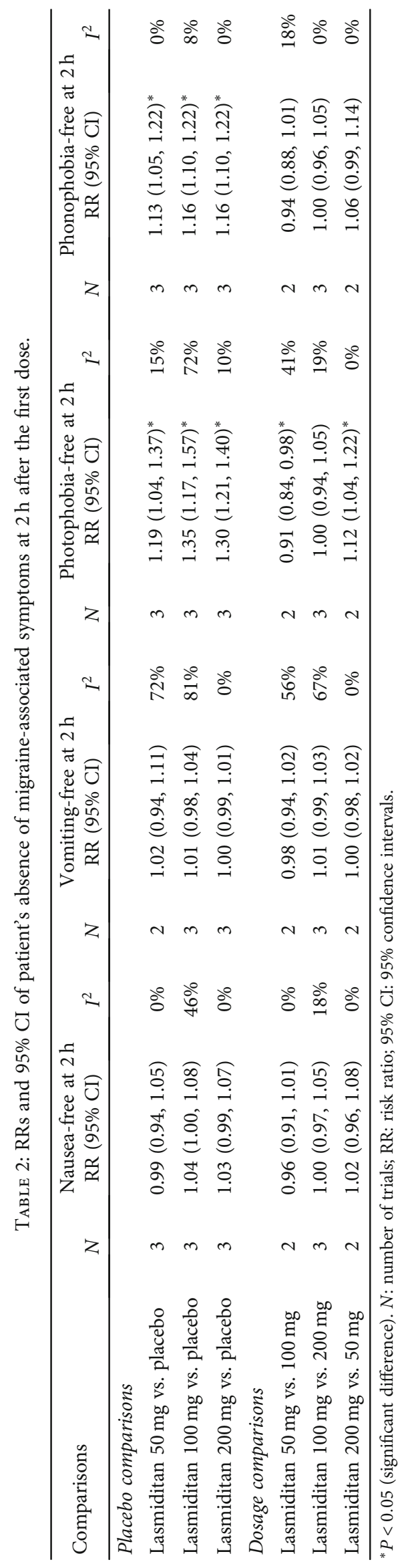




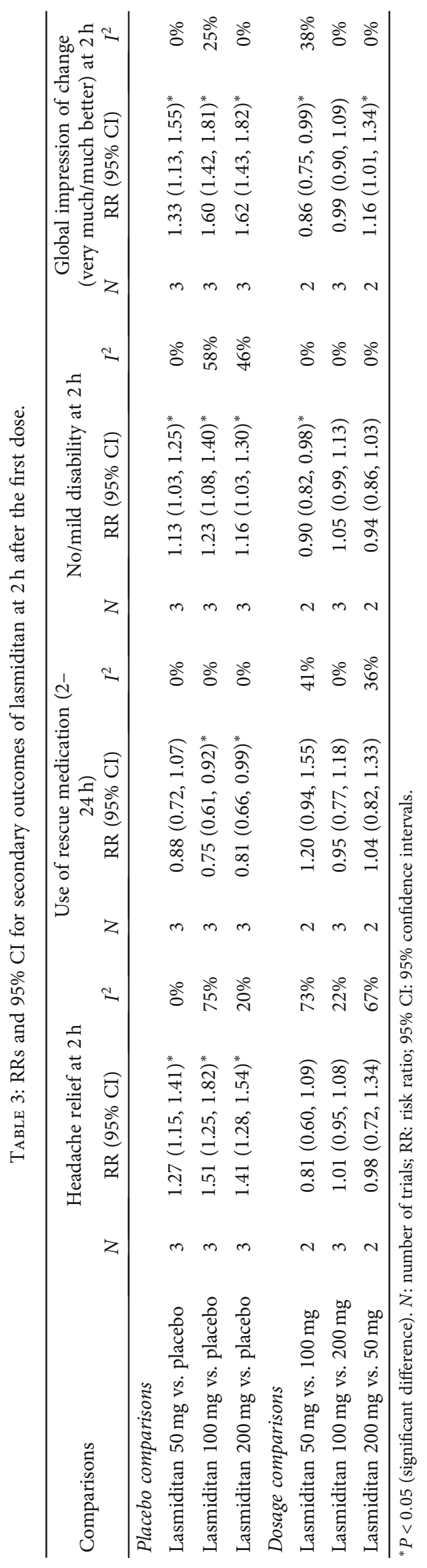




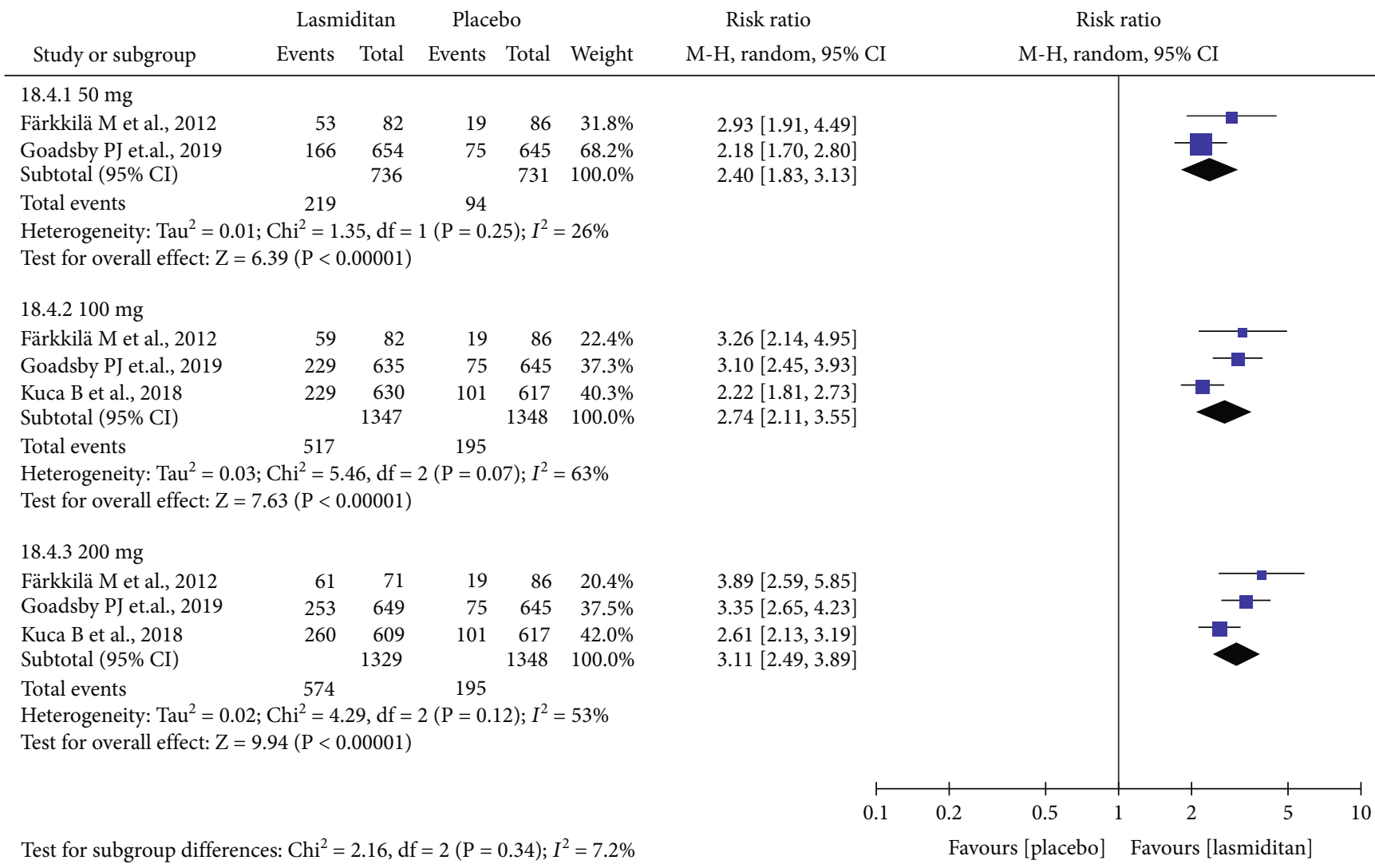

Figure 5: Forest plot: the proportion of migraineurs reporting TEAE (at least one) in the lasmiditan group (50 mg, $100 \mathrm{mg}$, and $200 \mathrm{mg}$ ) versus placebo after the first dose.

dosing of lasmiditan in the long-term follow-up should be conducted in the future. Currently, results in an open-label study have addressed that lasmiditan was safe and efficacious for the acute treatment of migraine from the long-term data [28].

In four RCTs, lasmiditan did not show triptan-like side effects including jaw, neck, and chest symptoms. Safety parameters such as heart rate, blood pressure, 12-lead electrocardiogram (ECG), hematology, biochemistry, and urine analysis did not show any clinically drug-related pathological abnormalities across the drug groups. No deaths related to lasmiditan were reported in the trials. In general, the safety profile of lasmiditan was satisfactory. We found that significantly more patients dosed with lasmiditan. $50 \mathrm{mg}$, $100 \mathrm{mg}$, and $200 \mathrm{mg}$ reported at least one TEAEs than patients receiving placebo. Most common TEAEs were CNS-related owing to central nervous system penetration. Most CNS-related TEAEs were mild to moderate in severity and short in duration, while varied CNS-related TEAEs had a high rate of occurrence (e.g., dizziness, paresthesia, fatigue, somnolence, and nausea). Dizziness symptom followed by vertigo and fatigue was the main complaint in CNS-related TEAEs. Lasmiditan crosses the $\mathrm{BBB}$ and binds to $5-\mathrm{HT}_{1 \mathrm{~F}}$ receptors located in trigeminal nerve terminals and other central or peripheral areas, but the specific site of action has not been definitely elucidated [12]. The study by Lucaites et al. [29] reported radioactive ligands, a potential tool to explore the localization and functions of the $5-\mathrm{HT}_{1 \mathrm{~F}}$ receptor, could bind significantly to $5-\mathrm{HT}_{1 \mathrm{~F}}$ receptors in the cerebellum, which could contribute to unwanted vertigo and dizziness symptom after drug administration. The incidence of CNS-related TEAEs is as high as $15 \%$ in some triptans [30], which seems to be more frequent in lasmiditan. Frequent occurrence of CNS-related TEAEs with triptans may reduce patient compliance, limit treatment initiation, and even impair workplace productivity and effectiveness despite the efficacy in aborting migraine attacks [30]. In a recent survey by the National Headache Foundation, up to $67 \%$ of patients reported delaying or avoiding their prescription medication for migraine due to concerns about side effects [31]. However, whether the high rate of CNS-related TEAEs may limit the clinical acceptability of lasmiditan still needs to be evaluated in long-term treatment studies. The pooled results of TEAEs should be interpreted with caution owing to the relatively high heterogeneity in reporting TEAEs, particularly for dizziness. The study by Färkkilä et al. [22] reported the differences between countries in the rates of dizziness, which suggested cultural and linguistic factors probably attributed to the heterogeneity of multicenter studies from different countries. In future studies, the procedure of reporting TEAEs should be modified to avoid possible overreporting of TEAEs.

The incidence of cardiovascular-related TEAEs reported by two studies was low. The cardiovascular events were generally mild or moderate in severity, and few were serious. Post hoc analysis for the incidence of cardiovascular events 


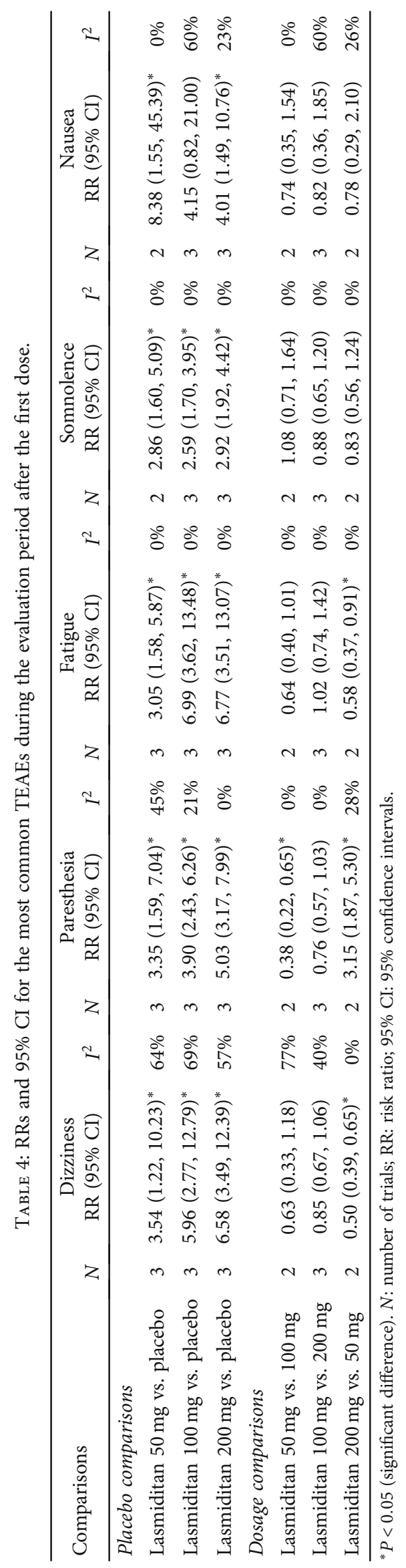




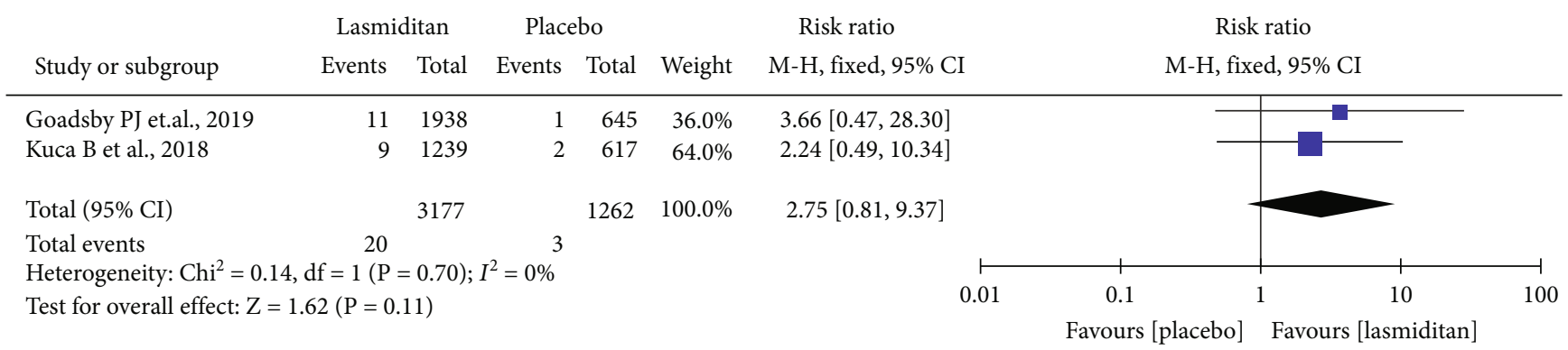

FIGURE 6: Forest plot: the incidence of cardiovascular-related TEAEs after the first dose.

showed that patients with at least one cardiovascular risk factor (CVRF) enrolled by the two studies accounted for $78.8 \%$ at baseline. The pooled estimate showed no difference in the incidence of cardiovascular-related TEAEs between lasmiditan and placebo, which provided insight into the safety of lasmiditan in patients with CVRFs. The difference in the incidence of cardiovascular-related TEAEs between patients with CVRFs and without CVRFs needs to be further investigated in the future, although the post hoc analysis of these two studies in phase III showed no difference [32].

Our meta-analysis evaluated the efficacy and safety of lasmiditan in different dosages $(50 \mathrm{mg}, 100 \mathrm{mg}$, and $200 \mathrm{mg}$ ). We found a dose-related response of lasmiditan for pain freedom. Based on the results of this meta-analysis, we found that lasmiditan $100 \mathrm{mg}$ and $200 \mathrm{mg}$ are more effective than lasmiditan $50 \mathrm{mg}$ in terms of pain-free, photophobia-free, and global impression of change (very much/much better), while lasmiditan $100 \mathrm{mg}$ and $200 \mathrm{mg}$ have no advantage over lasmiditan $50 \mathrm{mg}$ in terms of headache relief, phonophobia-free, and use of rescue medication. Compared with lasmiditan $100 \mathrm{mg}$, lasmiditan $200 \mathrm{mg}$ is more effective in achieving pain-free with a higher risk of reporting at least one TEAE. There are no significant differences between lasmiditan $100 \mathrm{mg}$ and $200 \mathrm{mg}$ in terms of headache relief, photophobia-free, phonophobia-free, no/mild disability, and global impression of change (very much/much better), use of rescue medication, and most common TEAEs. Consequently, lasmiditan with $200 \mathrm{mg}$ dose provides superior efficacy to $100 \mathrm{mg}$ in pain freedom at $2 \mathrm{~h}$ after the first dose. However, the clinical effect of the lasmiditan $200 \mathrm{mg}$ should be balanced against the higher risk of reporting at least one TEAE.

Some limitations in this meta-analysis should be considered. Firstly, few eligible studies were included in this metaanalysis. Subgroup analysis about confounding factors, such as sex, ethnicity, migraine severity, and concomitant preventive medications, has not been conducted in included trials due to the insufficient available trials and data. Secondly, the long-term efficacy and safety of lasmiditan should be validated by following up the participants using drugs repeatedly in further studies. Third, various headache characteristics of participants and efficacy assessment standards across studies resulted in significant heterogeneity between the studies in the meta-analyses. Headache pain relief was defined as a reduction of moderate or severe pain to mild or no pain in the study by Färkkilä et al. [22], or a reduction in headache severity from mild to none in studies by Kuca et al. and Goadsby et al. [23, 24]. Finally, there was a lack of active control groups. Future RCTs are recommended to provide a head-to-head comparison between lasmiditan and other acute drugs such as triptans.

\section{Conclusions}

Lasmiditan is effective and safe for acute migraine treatment, despite the high incidence of TEAEs. The clinical effect of lasmiditan $200 \mathrm{mg}$ is superior to lasmiditan $100 \mathrm{mg}$, while lasmiditan $100 \mathrm{mg}$ is better tolerated in the short-term follow-up. Superiority clinical trials are necessary to verify the clinical superiority of lasmiditan over the traditional antimigraine drugs and triptans. Additionally, further studies should be conducted to confirm the efficacy and tolerability of long-term clinical application.

\section{Data Availability}

The data used to support the findings of this study are included in the article and supplementary material files.

\section{Conflicts of Interest}

The authors declare that they have no conflict interests.

\section{Authors' Contributions}

Ping Gu, Cheng Chen, Qian Wu, Xin Dong, and Qi Wan contributed to the conception and design of the experiment. Cheng Chen, Ping Gu, and Xin Dong contributed to the database search and data extraction. Changhong Dong, Teng Wang, and Qian Wu analyzed the data. The original manuscript was written by Cheng Chen and Xin Dong. Qian Wu, Teng Wang, and Changhong Dong contributed to the revision of the manuscript. All authors read and approved the final manuscript. Ping Gu, Cheng Chen, and Qian Wu contributed equally to this work.

\section{Acknowledgments}

This work was supported by the National Natural Science Foundation of China (No. 81600970). 


\section{Supplementary Materials}

Supplementary 1. S1 File: PRISMA 2009 checklist.

Supplementary 2. S2 File: search strategies.

Supplementary 3. S3 File: forest plot: the proportion of migraineurs reporting TEAE (at least one) after the first dose between different dosage comparisons.

\section{References}

[1] H. C. Diener and D. W. Dodick, "Headache research in 2015: progress in migraine treatment," Lancet Neurology, vol. 15, no. 1, pp. 4-5, 2016.

[2] L. J. Stovner, E. Nichols, T. J. Steiner et al., "Global, regional, and national burden of migraine and tension-type headache, 1990-2016: a systematic analysis for the Global Burden of Disease Study 2016," Lancet Neurology, vol. 17, no. 11, pp. 954976, 2018.

[3] B. W. Friedman, J. West, D. R. Vinson, M. T. Minen, A. Restivo, and E. J. Gallagher, "Current management of migraine in US emergency departments: an analysis of the National Hospital Ambulatory Medical Care Survey," Cephalalgia, vol. 35, no. 4, pp. 301-309, 2015.

[4] W. J. Becker, “Acute migraine treatment in adults," Headache, vol. 55, no. 6, pp. 778-793, 2015.

[5] J. F. Soothill, “Migraine," Lancet, vol. 363, no. 9418, pp. 13981399, 2004.

[6] R. B. Lipton, D. C. Buse, D. Serrano, S. Holland, and M. L. Reed, "Examination of unmet treatment needs among persons with episodic migraine: results of the American Migraine Prevalence and Prevention (AMPP) study," Headache, vol. 53, no. 8, pp. 1300-1311, 2013.

[7] P. B. Rizzoli, "Emerging therapeutic options for acute migraine: focus on the potential of lasmiditan," Neuropsychiatric disease and treatment, vol. 10, pp. 547-551, 2014.

[8] M. D. Ferrari, K. I. Roon, R. B. Lipton, and P. J. Goadsby, “Oral triptans (serotonin $5-\mathrm{HT}_{1 \mathrm{~B} / 1 \mathrm{D}}$ agonists) in acute migraine treatment: a meta-analysis of 53 trials," Lancet, vol. 358, no. 9294, pp. 1668-1675, 2001.

[9] L. Lionetto, M. Borro, M. Curto et al., "Choosing the safest acute therapy during chronic migraine prophylactic treatment: pharmacokinetic and pharmacodynamic considerations," Expert opinion on drug metabolism \& toxicology, vol. 12, no. 4, pp. 399-406, 2016.

[10] P. J. Goadsby and L. Edvinsson, "The trigeminovascular system and migraine: studies characterizing cerebrovascular and neuropeptide changes seen in humans and cats," Annals of Neurology, vol. 33, no. 1, pp. 48-56, 1993.

[11] A. Negro, A. Koverech, and P. Martelletti, "Serotonin receptor agonists in the acute treatment of migraine: a review on their therapeutic potential," Journal of Pain Research, vol. 11, pp. 515-526, 2018.

[12] D. L. Nelson, L. A. Phebus, K. W. Johnson et al., "Preclinical pharmacological profile of the selective 5 -HT1F receptor agonist lasmiditan," Cephalalgia, vol. 30, no. 10, pp. 1159-1169, 2010.

[13] M. Hou, H. Xing, C. Li et al., "Short-term efficacy and safety of lasmiditan, a novel $5-\mathrm{HT}_{1 \mathrm{~F}}$ receptor agonist, for the acute treatment of migraine: a systematic review and meta-analysis," The Journal of Headache and Pain, vol. 21, no. 1, p. 66, 2020.
[14] Y. N. Lamb, "Lasmiditan: first approval," Drugs, vol. 79, no. 18, pp. 1989-1996, 2019.

[15] J. P. Higgins, D. G. Altman, P. C. Gotzsche et al., "The Cochrane Collaboration's tool for assessing risk of bias in randomised trials," BMJ, vol. 343, article d5928, 2011.

[16] X. Zeng, Y. Zhang, J. S. Kwong et al., "The methodological quality assessment tools for preclinical and clinical studies, systematic review and meta-analysis, and clinical practice guideline: a systematic review," Journal of Evidence-Based Medicine, vol. 8, no. 1, pp. 2-10, 2015.

[17] A. Pilgrim, B. Dussault, N. Rupniak, J. White, D. Mazur, and A. DiSanto, "COL-144, an orally bioavailable selective 5HT1F receptor agonist for acute migraine therapy," Cephalalgia, vol. 29, pp. 24-25, 2009.

[18] J. P. T. Higgins and S. G. Thompson, "Quantifying heterogeneity in a meta-analysis," Statistics in Medicine, vol. 21, no. 11, pp. 1539-1558, 2002.

[19] N. Terrin, C. H. Schmid, J. Lau, and I. Olkin, "Adjusting for publication bias in the presence of heterogeneity," Statistics in Medicine, vol. 22, no. 13, pp. 2113-2126, 2003.

[20] M. Egger, G. D. Smith, M. Schneider, and C. Minder, "Bias in meta-analysis detected by a simple, graphical test," $B M J$, vol. 315, no. 7109, pp. 629-634, 1997.

[21] M. D. Ferrari, M. Färkkilä, U. Reuter et al., “Acute treatment of migraine with the selective 5-HT1F receptor agonist lasmiditan-a randomised proof-of-concept trial," Cephalalgia, vol. 30, no. 10, pp. 1170-1178, 2010.

[22] M. Färkkilä, H. C. Diener, G. Géraud et al., "Efficacy and tolerability of lasmiditan, an oral $5-\mathrm{HT}_{1 \mathrm{~F}}$ receptor agonist, for the acute treatment of migraine: a phase 2 randomised, placebocontrolled, parallel-group, dose-ranging study," Lancet Neurology, vol. 11, no. 5, pp. 405-413, 2012.

[23] B. Kuca, S. D. Silberstein, L. Wietecha et al., "Lasmiditan is an effective acute treatment for migraine a phase 3 randomized study," Neurology, vol. 91, no. 24, pp. E2222-e2232, 2018.

[24] P. J. Goadsby, L. A. Wietecha, E. B. Dennehy et al., "Phase 3 randomized, placebo-controlled, double-blind study of lasmiditan for acute treatment of migraine," Brain, vol. 142, no. 7, pp. 1894-1904, 2019.

[25] P. Tfelt-Hansen, J. Pascual, N. Ramadan et al., "Guidelines for controlled trials of drugs in migraine: third edition. A guide for investigators," Cephalalgia, vol. 32, no. 1, pp. 6-38, 2012.

[26] Q. P. Ma, "Co-localization of 5-HT(1B/1D/1F) receptors and glutamate in trigeminal ganglia in rats," Neuroreport, vol. 12, no. 8, pp. 1589-1591, 2001.

[27] M. Capi, F. de Andrés, L. Lionetto et al., "Lasmiditan for the treatment of migraine," Expert opinion on investigational drugs, vol. 26, no. 2, pp. 227-234, 2017.

[28] J. L. Brandes, S. Klise, J. H. Krege et al., "Interim results of a prospective, randomized, open-label, phase 3 study of the long-term safety and efficacy of lasmiditan for acute treatment of migraine (the GLADIATOR study)," Cephalalgia, vol. 39, no. 11, pp. 1343-1357, 2019.

[29] V. L. Lucaites, J. H. Krushinski, J. M. Schaus, J. E. Audia, and D. L. Nelson, "[3H]LY334370, a novel radioligand for the 5-HT1F receptor. II. Autoradiographic localization in rat, guinea pig, monkey and human brain," Naunyn-Schmiedeberg's archives of pharmacology, vol. 371, no. 3, pp. 178-184, 2005.

[30] R. M. Gallagher and R. Kunkel, "Migraine medication attributes important for patient compliance: concerns about side effects may delay treatment," Headache, vol. 43, no. 1, pp. 36-43, 2003. 
[31] D. W. Dodick and V. Martin, "Triptans and CNS side-effects: pharmacokinetic and metabolic mechanisms," Cephalalgia, vol. 24, no. 6, pp. 417-424, 2004.

[32] R. E. Shapiro, H. M. Hochstetler, E. B. Dennehy et al., "Lasmiditan for acute treatment of migraine in patients with cardiovascular risk factors: post-hoc analysis of pooled results from 2 randomized, double-blind, placebo-controlled, phase 3 trials," The Journal of Headache and Pain, vol. 20, no. 1, p. 90, 2019. 